\title{
FOXO1 Fusion Positive
}

National Cancer Institute

\section{Source}

National Cancer Institute. FOXO1 Fusion Positive. NCI Thesaurus. Code C150627.

An indication that expression of a fusion containing sequences from FOXO1 has been detected in a sample. 